ESPAÇO TEMÁTICO: ESTADO, AUTORITARISMO E LUTA DE CLASSES

\title{
Autoritarismo e crise da democracia no Brasil: entre o passado e o presente
}

\author{
Sabrina Aparecida da Silva ${ }^{1}$ \\ https://orcid.org/0000-0002-3482-6009 \\ ${ }^{1}$ Universidade Federal de Santa Catarina, Programa de Pós-graduação em Serviço Social, Florianópolis, SC, Brasil
}

\begin{abstract}
Autoritarismo e crise da democracia no Brasil: entre o passado e o presente
Resumo: O presente artigo busca refletir sobre a crise da democracia liberal e a ascensão de ideias autoritárias no Brasil a partir do golpe parlamentar de 2016, mas principalmente após o início do governo de Jair Bolsonaro em 2018. A ascensão de manifestações de direita e de extrema direita no País, na atual conjuntura, nos faz pensar sobre a complexa relação histórica entre Estado, autoritarismo e democracia no Brasil. Assim sendo, percebemos que a incipiente democracia liberal brasileira é sustentada por uma cultura política autoritária reprodutora de desigualdades, racismos, conformismos e violências. Nesse sentido, em oposição aos movimentos assinalados antidemocráticos, a democracia popular deve ser construída a partir de novos valores éticos, morais, políticos, filosóficos e econômicos, radical ao capitalismo e condizente com práticas políticopedagógicas capazes de fomentar novos sujeitos sociais.
\end{abstract}

Palavras-chave: Autoritarismo. Democracia. Crise da democracia. Brasil.

Authoritarianism and the crisis of democracy in Brazil: between the past and the present

Abstract: This article intends to reflect on the crisis of liberal democracy and the rise of authoritarian ideas in Brazil since the 2016 parliamentary coup, but mainly after the start of Jair Bolsonaro government in 2018. The rise of manifestations from the right and extreme right supporters in the country, during the current conjuncture, makes us think about the complex historical relation between State, authoritarianism and democracy in Brazil. Therefore, we realize that the incipient brazilian liberal democracy is supported by an authoritarian political culture which reproduces inequalities, racisms, conformities and violence. In this sense, in opposition to the well-known undemocratic movements, popular democracy must be built through new ethical, moral, political, philosophical and economical values, being radical to capitalism and consistent with political pedagogical practices capable of fostering new social subjects.

Keywords: Authoritarianism. Democracy. Crisis of Democracy. Brazil.

Recebido em 26.06.2020. Aprovado em 17.07.2020. Revisado em 28.09.2020.

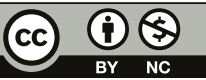

Este é um artigo publicado em acesso aberto (Open Access) sob a licença Creative Commons Attribution NonCommercial, que permite uso, distribuição e reprodução em qualquer meio, sem restrições desde que sem fins comerciais e que o trabalho original seja corretamente citado. 


\section{Introdução}

Diferentemente dos contextos e dos processos históricos europeus, a conformação do Estado nacional brasileiro nasceu referenciada em relações sociais de poder, de opressão e de dominação de classe com variadas ramificações e especificidades. Ou seja, a ideia de Estado no Brasil surgiu como a "única entidade que podia ser manipulável desde o início, a partir da situação de interesses das elites nativas, mas com vistas a sua progressiva adaptação à filosofia política do liberalismo" (FERNANDES, 2005, p. 53). Ainda conforme Florestan Fernandes (2005), historicamente a heteronomia liberal do País atendeu aos interesses da economia mundial, a qual detinha o controle e o monopólio do mercado exterior e as estruturas sociais de poder e de dominação pela burguesia nacional.

De modo geral, a cultura política e histórica brasileira e dos países colonizados no mundo possuem similaridades sociais, políticas, culturais e econômicas, pois quando falamos sobre desigualdades, autoritarismos, opressões, racismos, dentre outros elementos históricos, estamos tratando de uma cultura política e social estruturada em visões de mundo autoritárias, clientelistas e advindas do projeto de sociedade da classe dominante. Estas ideologias seletivas e segregacionistas são vetores concretos de conformação e de naturalização das relações sociais vigentes de desigualdades e de opressões sociais, as quais impossibilitam à grande parte da classe trabalhadora o acesso à cidadania, à democracia e à justiça social. Refletir sobre a conformação do Estado brasileiro é saber que a "democracia não é um ponto de chegada [...], é um momento de conflito" (MIGUEL, 2018, p. 08), ou seja, o Estado Democrático de Direito inaugurado após a Constituição Federal de 1988 não se concretizou para todos os grupos sociais, visto que este modelo de democracia e de cidadania liberais não visam à igualdade de oportunidades entre os grupos.

Em vista destes elementos históricos afirmados, o presente artigo objetiva refletir sobre a realidade brasileira e seu cenário político entre o golpe parlamentar de 2016 e o primeiro momento do governo de Jair Bolsonaro em 2018, momento este em que ocorre a ascensão de manifestações políticas de direita e de extrema direita pelo País, com pautas obscuras, antidemocráticas e militaristas. Tais movimentos políticos de parte da sociedade nos fazem pensar sobre a complexa tríade histórica entre Estado, autoritarismo e democracia no Brasil. Partimos do entendimento de que o autoritarismo é historicamente um eficiente "instrumento para adequar a sociedade civil à estrutura econômica" (GRAMSCI, 2011, p. 324), pela via da coerção, seja ela militar, jurídica ou policial.

Dessa forma, o artigo num primeiro momento buscará refletir sobre os conceitos de Estado e de autoritarismo, a partir das Ciências Sociais e Humanas, enquanto parâmetros de interpretação históricocientífica para chegarmos à compreensão da ascensão das mobilizações de direita e de extrema direita no Brasil. O segundo momento do trabalho trata dos conceitos de democracia e crise de democracia, a partir do pensamento de Antonio Gramsci, trazendo luz à discussão: qual é a democracia que queremos para o Brasil?

\section{A ascensão das manifestações autoritárias nas ruas: do golpe parlamentar à eleição de Bolsonaro}

A concepção histórica e teórica de Estado autoritário nos remete a relações sociais e políticas imbricadas em longos processos de colonização, de exploração e de expropriação da terra e do trabalho por grupos da elite política nacional e seus ramos internacionais. Seguindo neste complexo processo histórico, nascem os partidos, os sindicatos e os movimentos sociais da classe trabalhadora, que podem disputar os espaços políticos e apresentar propostas para o desencadeamento de uma nova cultura política na sociedade civil. Assim, "deve-se compreender que a sociedade civil não é uma zona neutra. Nela, os vários elementos da sociedade não operam e competem em igualdade de condições, de forma homogênea, independentemente das relações de força e poder" (SIMIONATTO, 2012, p. 53-54). A sociedade civil na perspectiva gramsciana, oposta à concepção liberal de mercado ou de terceiro setor, compreende as disputas políticas e econômicas dentro do Estado burguês, no qual a neutralidade é o grande paradoxo do neoliberalismo, por entendermos que o Estado capitalista não é neutro aos interesses da classe dominante.

O autoritarismo no Brasil, enquanto expressão histórico-cultural e política, coloca-se entre o conservadorismo das elites locais no poder e a ampliação de seus privilégios políticos, econômicos e culturais no Estado. Ou seja, o conceito de autoritarismo compreende a negação da igualdade entre os homens, no qual ganham destaque os 
princípios da hierarquia, da ordem e da harmonia social (HACKENHAAR, 2019). Numa perspectiva elitista do conceito, a sociedade e os indivíduos são considerados desiguais por natureza, pois são resultados de uma 'vontade divina' que justificaria a desigualdade, a hierarquização, a obediência e a consequente exclusão/negação da maior parte dos sujeitos sociais dos centros decisórios do Estado. A liberdade de expressão, de pensamento e de mobilização sofre restrições, assim como os movimentos sociais, os partidos políticos e os sindicatos da classe trabalhadora são silenciados, pois representam o conflito e a desordem social (BOBBIO, 1998, p. 94). Para Wanderley Guilherme dos Santos $(1978,1988)$, o autoritarismo é uma fórmula para impedir que o conflito político institucionalizado permita um ajuste entre o governo (polis) e a sociedade (demos), o qual, através de uma contínua reestruturação da sociedade, pode reduzir ou aumentar as disparidades socioeconômicas e criar um novo sistema de governo que amplie o acesso da sociedade a este e limite a interferência da polis no demos. Já para Boris Fausto (2001), o autoritarismo pode ser entendido como uma restrição à mobilização das massas, em que a sociedade consegue manter uma relativa independência em relação ao Estado, que tolera uma esfera privada de pensamento e de crença. Todavia, independente dos autores e das definições de autoritarismo, ao que parece, o cerne deste conceito está no temor das agitações sociais e do aumento da participação política nas esferas do Estado pelas classes populares.

Em vista destes elementos do autoritarismo, a "questão da democracia inclusive em seus limites puramente formal-liberais é assim a questão decisiva da vida brasileira", pelo seu "caráter elitista e autoritário que assinalou toda a evolução política, econômica e cultural do Brasil, mesmo em seus breves períodos “democráticos"” (COUTINHO, 1979, p. 1). Assim, os chamados períodos de crise da democracia são todos aqueles "atravessados por guerras, revoluções, golpes de Estado, contrarrevoluções etc. Por vezes [...] podem demorar anos para terem suas contradições solucionadas, gerando um período significativo de instabilidade política" (DEMIER; MELO, 2018, p. 256).

De certa maneira, podemos dizer que a conjuntura política que acompanhou as Jornadas de Junho de 2013 reativou e impulsionou as forças reacionárias e neoconservadoras adormecidas desde o golpe militar de 1964, as quais permanecem motivadas às pautas antidemocráticas, como por exemplo, o retorno da ditadura militar. O regresso dos grupos de direita às ruas, após décadas de ostracismo, "demonstrouo inegável crescimento, junto aos setores médios da sociedade brasileira, do ideário reacionário, o qual coaduna aspectos ultraliberais com outros tradicionalistas" (DEMIER; MELO, 2018, p. 267). Entretanto, convém destacar que essas manifestações reacionárias e neoconservadoras não estavam presentes no início das Jornadas de Junho de 2013, "antes da burguesia ter conseguido pautar o movimento -, e, de certa forma, os atos reacionários podem até ser considerados como uma 'resposta de determinados setores das classes dominantes ao temor despertado' em 2013”. (DEMIER; MELO, 2018, p. 267). Temos assim, um heterogêneo e novo movimento político composto por uma direita autoritária que contribuiu para o aprofundamento da crise capitalista, possibilitando a ascensão de grupos ultraliberais na direção do Estado e reproduzindo as velhas táticas políticas de opressão, de manipulação e de clientelismo, adeptas ao discurso do anticomunismo e do combate à corrupção.

O golpe parlamentar de 2016 mostrou claramente o seu caráter reacionário nas eleições presidenciais de 2018, quando, após a prisão de Luiz Inácio Lula da Silva e sua consequente impossibilidade de concorrer ao pleito eleitoral presidencial, Jair Bolsonaro foi eleito presidente do Brasil, com o apoio das burguesias nacional e internacional, de setores da classe média e segmentos populares conservadores. A eleição de Bolsonaro trouxe à tona movimentos reacionários e neoconservadores, os quais passaram a realizar manifestações públicas com teor racista, sexista, misógino e homofóbico. Neste cenário político surgem as mobilizações antidemocráticas de direita e de extrema direita, contudo, "não há diferença de natureza entre os movimentos que gestam Temer e os que sustentam Bolsonaro. Há, sim, gradações e arranjos específicos" (MASCARO, 2019, p. 26).

Em oposição a esse contexto, durante e após a eleição de 2018, significativas mobilizações populares e democráticas cresceram, seja através de passeatas ou de protestos organizados nas redes sociais pelos diversos movimentos sociais da classe trabalhadora. Dentre essas mobilizações progressistas podemos destacar os movimentos feministas, indígenas, ambientalistas, rurais, estudantis, sindicais, religiosos, dentre outros, os quais formaram segmentos e organizações sociais ativas e favoráveis a uma ampla rede democrática contra o conservantismo dos grupos dominantes no poder. Todavia, também entendemos que desde a chegada de Jair Bolsonaro à presidência do Brasil a participação política das classes populares tem sido cancelada pelo uso desenfreado de decretos ou de medidas autoritárias e antidemocráticas, as quais retiram autonomia política, econômica e cultural das classes populares. O embrionário movimento político-popular das classes subalternas 
está longe de abarcar uma luta anticapitalista, mas adensa a correlação de forças sociais pelo fim da barbárie social.

A Reforma Trabalhista e a regulamentação da Lei das Terceirizações aprovadas no governo de Michel Temer contribuíram significativamente, juntamente com os discursos políticos e ideológicos neoliberais da mídia burguesa, à Reforma da Previdência. Assim sendo, no dia 13 de novembro de 2019 entrou em vigor no governo de Jair Bolsonaro a 'Nova' Reforma da Previdência, através da Emenda Constitucional de nº 103/2019 (BRASIL, 2019), a qual desde o governo de Michel Temer aguardava aprovação. O continuísmo econômico ultraliberal do atual governo federal coloca o País numa dependência econômica ainda maior e subalterna ao capital financeiro internacional.

Essas medidas neoliberais e de contrarreformas do Estado brasileiro revelam a tendência política e econômica de redução dos direitos sociais da classe trabalhadora. Um fator relevante e produto desta crise democrática é a informalidade (soma dos trabalhadores sem carteira, dos trabalhadores domésticos sem carteira, dos trabalhadores familiares auxiliares e trabalhadores informais) que atinge $41,1 \%$ da população, ou seja, a soma total equivalente a 38,4 milhões de pessoas, o maior contingente desde 2016. Segundo os dados do Instituto Brasileiro de Geografia e Estatística (IBGE), o desemprego teve uma baixa superficial, onde a taxa média de desocupação caiu de 12,3\% em 2018 para 11,9\% em 2019. Contudo, o aumento dos trabalhadores informais (sem garantias trabalhistas e sociais) atingiu um crescimento recorde de $87,7 \%$ nos últimos cinco anos (NERY, 2020). Ou melhor, "diversamente de 1964/1968, o Brasil não encarou em 2019 uma conjuntura de crescimento interno e internacional, mas uma crise econômica estrutural e uma desaceleração internacional" (COGGIOLA, 2019, p. 152).

Nesse sentido, o golpe parlamentar de 2016 agravou a situação da classe trabalhadora pobre e, ao mesmo tempo, reafirmou o lugar do Estado brasileiro na divisão internacional do trabalho, internalizado por "uma economia primária e extrativa; ausência de preocupação [...] tecnológica; destruição de nossa pouca soberania; empregos precários e de baixo valor; crescimento da desigualdade funcional, de renda, regional; crescimento da pobreza e da miséria" (PAULANI, 2019, p. 55).

\section{Crise da democracia: qual crise? ${ }^{1}$}

A "crise da democracia é atualmente um dos temas prediletos dos jornais e de diferentes atividades e rodas de conversa [...]. Significaria isto um alarme máximo? No entanto, a pergunta a ser formulada é esta: 'o que exatamente encontra-se em crise?"' (HIRSCH, 2019, p. 81). Sabemos que até o momento, a "democracia liberal-burguesa não conseguiu (e está bem longe de conseguir) expressar a "vontade do povo", visto que o 'povo' na "democracia liberal-burguesa" apenas pode interferir na cogestão do Estado, a partir de critérios definidos, e com isso, suas necessidades permanecem subalternas aos interesses da classe dominante (HIRSCH, 2019, p. 83).

As indagações acima de Joachim Hirsch (2019) são atuais para pensarmos sobre a realidade brasileira quando sabemos que historicamente a democracia liberal colocada representa a hegemonia da classe dominante. Quando esta hegemonia entra em crise num determinado contexto, ela "perde o consenso, ou seja, este grupo não mais é 'dirigente', mas, unicamente 'dominante' e detentor da pura força coercitiva do Estado" (GRAMSCI, 2007, p. 184). Isso significa dizer que nas crises de hegemonia existem duas situações visíveis: na primeira, as classes dominantes se rearticulam pela força coercitiva, pela via do autoritarismo; enquanto numa segunda situação, as classes dominadas revertem-na através das lutas sociais, ocupando no Estado espaços centrais para a formação de sua hegemonia; formando novos sujeitos na tomada do poder; até tornarem-se dirigentes e dominantes (GRAMSCI, 2007).

O período de expansão colonial e industrial pelo mundo pós 1870 demarcou o nascimento de uma "estrutura maciça das democracias modernas, seja como organizações estatais, seja como conjunto de associações na vida civil, constitui para a arte política algo similar às 'trincheiras' e às fortificações permanentes [...]" (GRAMSCI, 2007, p. 24). Através do pensamento de Gramsci sobre a situação da Itália após a Primeira Guerra Mundial, podemos dizer que a democracia organizou o fascismo quando sentiu que não podia mais resistir, mesmo num quadro de liberdades apenas formais, à pressão da classe trabalhadora. $\mathrm{O}$ fascismo, desagregando a classe operária, voltou a dar possibilidade de existência à democracia (GRAMSCI, 2004, p. 282). O fascismo 
italiano se organizou a partir da base, ou seja, estudou o movimento operário, avaliou o momento certo de agir e contou consequentemente com a 'passividade' do movimento dos trabalhadores nas ruas.

Além disso, o conceito de democracia não pode estar restrito ao sentido em que operam as filosofias e as ideologias pertencentes aos grupos liberais e, hoje, neoliberais. A democracia de tipo liberal tradicional nasceu dos movimentos históricos de expansão do domínio burguês para a construção do Estado pautado em regras, valores e princípios morais, éticos, políticos e filosóficos que conformaram a sociabilidade capitalista moderna. Assim, as chamadas crises da democracia liberal no mundo se manifestam em diferentes períodos históricos, pois em cada crise do capital pode haver novos golpes políticos, parlamentares, civis ou militares de Estado, incluindo os períodos de guerra e as ditaduras militares. Contudo, nestes momentos de crise da democracia liberal, quando ocorre o avanço das forças reacionárias e conservadoras no mundo, deve-se somar às "lutas sociais através dos movimentos sociais que buscam fortalecer práticas democráticas na luta por direitos [...]" (NEVES, 2016, p. 24).

A democracia brasileira constitucional de 1988 derivou-se de um longo processo de lutas e de efervescência popular dos movimentos sociais e sindicais, das camadas médias trabalhadoras e da pequena burguesia, pela redemocratização do País ao longo das décadas de 1970 e 1980. Entretanto, se refletirmos acerca de que crise estamos falando, percebemos que é uma crise estrutural do capital. A crise da democracia liberal no Brasil sempre esteve presente para as populações das periferias urbanas e rurais, para os indígenas, negros, mulheres pobres, imigrantes, dentre outros grupos sociais subalternizados. A democracia liberal que temos convive com o trabalho escravo, com o subemprego, com a fome, com a miséria, com o analfabetismo e com a exploração infanto-juvenil. À vista disso, a pergunta que devemos responder é a seguinte: qual é a democracia que queremos construir no Brasil?

Esta democracia liberal convive com uma grave crise que se generalizou nas instituições públicas e democráticas brasileiras, provocada pelos interesses da burguesia nacional e de seus ramos internacionais, os quais não aceitam mais a continuidade do contrato social regido desde a Constituição Federal de 1988. O Estado brasileiro no modelo neoliberal continua a sustentar a reprodução ampliada do capital internacional, não mais atendendo minimamente as necessidades básicas da população pobre e explorada por este sistema societário. Ou dito de outra maneira, para cada momento histórico existe um determinado caráter para o Estado nacional e para as noções de democracia e de liberdade, as quais são disputadas no campo da política e da cultura, dado o seu caráter histórico-estrutural.

A análise e o reconhecimento das correlações de forças em confronto com os interesses da classe dominante não podem ser anulados nestes períodos. Com o fim da ditadura militar, no final da década de 1980, não obtivemos realmente um Pacto Social-Popular que contemplasse as necessidades do povo brasileiro. As reformas de base como a agrária, a urbana, a fiscal, a universitária, dentre outras, as quais poderiam realmente democratizar o Estado, nunca saíram do papel ou das boas intenções de parte dos grupos de parlamentares progressistas.

Em concordância com Neves (2016, p. 27), "a democracia que queremos se manifesta no reconhecimento e na identidade coletiva dos diferentes movimentos sociais que se espalham no mundo e na sociedade". A superação da subordinação política dos trabalhadores é um primeiro passo e se faz necessária para que possamos "radicalizar a democracia" e "colocar em prática no cotidiano da política transparência nas ações, socialização das informações, retorno às bases representativas, ampliação dos processos decisórios e fortalecimento dos espaços públicos participativos" (NEVES, 2016, p. 28). Os vínculos de solidariedade entre as camadas das classes subalternas e os espaços de socialização da política fundados numa educação crítica e não religiosa dos processos sociais devem ser fomentados e consecutivamente reproduzidos nesta sociedade.

Desta forma, as conquistas participativas e de controle social após a Constituição Federal de 1988, como os conselhos de direitos, os fóruns populares, os comitês de bairro, as conferências de políticas públicas, os orçamentos participativos, as ouvidorias públicas, as defensorias e os plebiscitos, não podem ser descartados do processo de emancipação política da classe trabalhadora. Estes arranjos e instrumentos democráticos e participativos fizeram e fazem parte do árduo processo de democratização do Estado brasileiro, diferentemente do que dita a atual cultura autoritária governista.

A construção de uma nova cultura no País leva em consideração, a "reforma intelectual e moral", que para Gramsci (2011, p. 94-95) refere-se à formação de uma nova "vontade coletiva" pensada a partir 
das necessidades concretas da classe trabalhadora. Sendo assim, para se construir um novo modelo de sociedade sem exploração, sem analfabetismo, sem fome e sem violências, novas práticas políticas, participativas e democráticas devem ser fomentadas e fortalecidas, mas não pelas mãos do mercado. Os valores sociais verbalizados pelo capital são antidemocráticos, pois objetivam a individualidade, a concorrência, a competição, o fetichismo da mercadoria, o lucro empresarial, entre outras tendências ideológicas que abarcam o capitalismo.

A democracia popular impõe a organização política e filosófica constante das classes subalternas em seus organismos representativos de classe, numa dialética do pluralismo, que envolve o diálogo e a luta conjunta entre os diferentes sujeitos sociais progressistas na construção de uma democracia realmente para todos. Lembrando-se que a 'liberdade' para a luta social e a luta política contra o capitalismo sempre será restrita, manipulada ou distorcida pela mídia burguesa. Segundo as reflexões de Gramsci, "a liberdade de organização é concedida pelos burgueses aos trabalhadores somente quando eles têm a segurança de que estes últimos estão reduzidos a uma tal situação que podem se servir desta liberdade" (GRAMSCI, 2004, p. 282). A liberdade democrática e capitalista envolve a comodidade econômico-corporativa da classe dominante burguesa e do grande capital.

A crise da democracia liberal é a crise da ordem capitalista, pois ela nasce do conjunto de costumes, direitos e de deveres ensinados desde a infância, principalmente através da escola, cujo papel central é desempenhar a manutenção desta sociedade, baseada numa cultura conformista, individualista, antidemocrática, antipopular e antirrevolucionária. Como destacado por Gramsci (2007, p. 249), a "classe dirigente [...] 'impõe' a toda sociedade aquelas normas de conduta que estão mais ligadas à sua razão de ser e ao seu desenvolvimento". E por conta desta cultura política autoritária, que é própria das relações sociais capitalistas, no Brasil e em boa parte do mundo, as classes subalternas estão submetidas às visões de mundo da classe dominante, e, como consequência das imposições, a conquista de uma democracia popular e radical a este sistema dominante é um longo processo de aprendizagem política e cultural das massas com seus intelectuais e entidades de resistência.

\section{Considerações finais}

A formação sócio-histórica brasileira aconteceu numa relação complexa entre autoritarismos e resistências, pois ela foi sustentada por uma cultura racista e de classe, que oprime e domina os grupos sociais historicamente marginalizados. Por conta dessa formação do Estado brasileiro, a democracia liberal que temos necessita ser recriada e pensada a partir de novos valores sociais, éticos e políticos, numa perspectiva crítica, plural e participativa dos sujeitos oprimidos, aliada a práticas político-pedagógicas junto aos movimentos sociais das camadas populares. Além disso, a democracia liberal sempre esteve em colapso pela direção empresarial imposta pelos grupos ultraliberais e tradicionais ligados ao Estado nacional, ou seja, hoje o capital financeiro controla o cenário político das democracias liberais contemporâneas, sejam elas centrais ou periféricas. Consequentemente, as lutas sociais e políticas dos grupos subalternos contra as opressões de classe, de gênero, de raça e etnia devem estar correlacionadas à superação desta desigual e opressora sociabilidade capitalista.

As ideologias e as práticas políticas autoritárias que sustentam as manifestações de direita e de extrema direita na atual cena contemporânea seguem a via da disseminação do ódio através de notícias falsas, as quais na maioria das vezes pregam a violência e a intolerância com indígenas, LGBTs, afrodescendentes, mulheres, idosos, imigrantes, pessoas com deficiências, povos ribeirinhos e jovens das periferias. Para alterar e/ou superar este dramático contexto brasileiro, entendemos que reinventar a democracia brasileira numa perspectiva crítica e plural é conceber "novos sujeitos ético-políticos não apenas libertos e autônomos, mas intencionados e preparados para governar o mundo com um projeto realmente alternativo de forma a realizar uma democracia popular radicalmente diferente" (SEMERARO, 2009, p. 192).

\section{Referências}

BOBBIO, N. Dicionário de política. 11. ed. Brasília: Editora da UnB, 1998. 
BRASIL. [Constituição (1988)]. Emenda constitucional n 103, de 12 de novembro de 2019. Altera o sistema de previdência social e estabelece regras de transição e disposições transitórias. Brasília, DF: Presidência da República, 2019. Disponível em: http://www. planalto.gov.br/ccivil_03/constituicao/emendas/emc/emc103.htm. Acesso em: 12 jun. 2020.

COGGIOLA, O. Entre FHC, Lula e Bolsonaro. Elementos para uma histórica econômico-política do Brasil (1979-2019). São Paulo: Liberars, 2019.

COUTINHO, C. N. A democracia como valor universal. Marxists, [S.1.], 1979. Disponível em: https://www.marxists.org/portugues/ coutinho/1979/mes/democracia.htm. Acesso em: 12 jun. 2020.

DEMIER, F.; MELO, D. Onda conservadora, crise orgânica e cesarismo de toga no Brasil. In: BOSCHETTI, I.; BEHRING. E.; LIMA, R. de L. de (org.). Marxismo, política social e direitos. 1. ed. São Paulo: Cortez Editora, 2018.

FAUSTO, B. O pensamento nacionalista autoritário. Rio de Janeiro: Jorge Zahar, 2001.

FERNANDES, F. A revolução burguesa no Brasil: ensaio de interpretação sociológica. 5. ed. São Paulo: Globo, 2005.

GRAMSCI, A. Cadernos do Cárcere. Introdução ao estudo da filosofia. A filosofia de Benedetto Croce. 5. ed. Rio de Janeiro: Civilização Brasileira, v. 1, 2011.

GRAMSCI, A. Cadernos do Cárcere. Maquiável. Notas sobre o Estado e a Política. 3. ed. Rio de Janeiro: Editora Civilização Brasileira, v. 3, 2007.

GRAMSCI, A. Escritos políticos. Rio de Janeiro:Civilização Brasileira, v. 2, 2004.

HACKENHAAR, C. O integralismo em Santa Catarina e a tentativa de golpe em março de 1938. 2019. Tese (Doutorado em História Social) - Instituto de Filosofia e Ciências Humanas, Universidade Federal do Rio Grande do Sul, Porto Alegre, 2019.

HIRSCH, J. Crise da democracia: qual crise? Revista da Boitempo, São Paulo, n 32, $3^{\circ}$ trimestre, p. 81-87, maio 2019.

MASCARO, A. L. Dinâmica da crise e do golpe: de Temer a Bolsonaro. Revista da Boitempo, São Paulo, n. 32, ed. 1, p. 25-32, maio 2019. MIGUEL, L. F. Dominação e resistência: desafios para uma política emancipatória. 1. ed. São Paulo: Boitempo, 2018.

NERY, C. Desemprego cai para 11,9\% na média de 2019; informalidade é a maior em 4 anos. Agência de Notícias, 31 jan. 2020. Disponível em: https://agenciadenoticias.ibge.gov.br/agencia-noticias/2012-agencia-de-noticias/noticias/26741-desemprego-cai-para11-9-na-media-de-2019-informalidade-e-a-maior-em-4-anos. Acesso em: 12 jun. 2020.

NEVES, A. V. Ameaças à democracia hoje: desafios contemporâneos. In: NEVES, A. V. Democracia e Participação Social: desafios contemporâneos. Campinas: Papel Social, 2016.

PAULANI, L. M. Bolsonaro, o ultraliberalismo e a crise do capital. Revista da Boitempo, São Paulo, n 32, $3^{\circ}$ trimestre, p. 48-56, maio/2019.

SANTOS, W. G. Paradoxos do Liberalismo. Rio de Janeiro: Vértice, 1988.

SANTOS, W. G. Poder e política: crônica do autoritarismo brasileiro. Rio de Janeiro: Forense-Universitária, 1978.

SEMERARO, G. Libertação e Hegemonia: realizar a América Latina pelos movimentos populares. São Paulo: Ideias e letras, 2009.

SIMIONATTO, I. Razões para continuar utilizando a categoria sociedade civil. In: CASTRO, A. T. B.; NEVES, A. V. Sociedade civil e serviço social: uma perspectiva crítica. Brasília: UNB, 2012. p. 33-58.

\section{Nota}

1 O título faz referência ao texto de Joachim Hirsch (2019).

\section{Sabrina Aparecida da Silva}

sabrina.ufsc@gmail.com

Doutoranda em Serviço Social pelo Programa de Pós-graduação em Serviço Social da Universidade Federal de Santa Catarina (UFSC)

Mestra em Serviço Social pelo Programa de Pós-graduação em Serviço Social da Universidade Federal de Santa Catarina (UFSC)

\section{UFSC}

Centro Socioeconômico - CSE.

Campus Reitor João David Ferreira Lima.

Trindade - Florianópolis/SC.

CEP: 88040-900. 


\section{Agradecimentos}

Ao Departamento de Serviço Social da UFSC, ao Programa de Pós-Graduação em Serviço Social da UFSC e a Coordenação de Aperfeiçoamento de Pessoal de Nível Superior - Brasil (CAPES).

Agência financiadora

Não se aplica.

Contribuições da autora

Não se aplica.
Aprovação por Comitê de Ética e consentimento para participação

Não se aplica.

Consentimento para publicação

Consentimento da autora.

Conflito de interesses

Não há conflito de interesses. 